\title{
PENGARUH PERBEDAAN RASIO INDUKAN PUYUH JANTAN HYBRID DAN PUYUH BETINA JEPANG (Coturnix coturnix japonica) TERHADAP KUALITAS DOQ
}

\author{
(The Effect of Differences in the Ratio of Sires of Male Hybrid Quails and Japanese \\ Female Quails (Coturnix coturnix japonica) to DOQ Quality)
}

\author{
Ajria, Herawati Latif, M. Aman Yaman \\ Program Studi Peternakan, Fakultas Pertanian, Universitas Syiah Kuala
}

\begin{abstract}
Abstrak. Permasalahan yang terjadi saat ini di berbagai peternakan puyuh ialah penyediaan bibit sendiri sebagai indukan dengan cara perkawinan yang ada hubungan kekerabatan dekat (sedarah) tanpa persilangan dengan bibit baru dari luar. Akibatnya bibit-bibit yang dihasilkan dari hasil perkawinan tersebut mengalami kecacatan karena pengaruh inbreeding yang telah melampaui batas. Salah satu upaya untuk meningkatkan kualitas puyuh yaitu dengan dilakukannya perkawinan silang (Cross Breeding) pada indukan puyuh. Perkawinan silang ini sangat baik jika dilakukan antara dua jenis puyuh yang memiliki kelebihan yang berbeda seperti puyuh Jepang (Coturnix coturnix japonica) dan puyuh Hybrid. Tujuan dari penelitian ini adalah untuk mengetahui pengaruh perbedaan rasio indukan puyuh jantan Hybrid dan puyuh betina Jepang (Coturnix coturnix japonica) terhadap kualitas DOQ. Parameter yang diamati yaitu fertilitas, kematian embrio, daya tetas, berat tetas, mortalitas dan rasio DOQ jantan betina. Berdasarkan data hasil penelitian dapat disimpulkan bahwa perbedaan rasio indukan puyuh Hybrid jantan dan puyuh betina Jepang tidak memberikan pengaruh yang nyata terhadap fertilitas, kematian embrio, daya tetas, berat tetas, mortalitas dan rasio DOQ jantan betina. Meskipun tidak berbeda nyata, fertilitas dan daya tetas tertinggi hasil persilangan puyuh jantan Hybrid dan puyuh betina Jepang (Coturnix coturnix japonica) yaitu pada $\mathrm{P}_{4}$ dengan perbandingan indukan dan pejantan 4:4.
\end{abstract}

Kata kunci: Inbreeding, perkawinan silang, puyuh Jepang, puyuh Hybrid

\begin{abstract}
The problem that is currently occurring at various quail farms is the supply of own seeds as sires by means of marriage that have close kinship (blood) without crossing with new seeds from outside. As a result the seeds produced from the results of the marriage experience disability because of the influence of inbreeding that has exceeded the limit. One effort to improve the quality of quail is by doing cross breeding on quail breeders. Crossbreeding is very good if done between two types of quail that have different advantages such as Japanese quail (Coturnix coturnix japonica) and Hybrid quail. The purpose of this study was to determine the effect of differences in the ratio of sires of male hybrid quails and Japanese female quails (Coturnix coturnix japonica) to DOQ quality. The parameters observed were fertility, embryo death, hatchability, hatch weight, mortality and female DOQ ratio. Based on the research data it can be concluded that the differences in the ratio of male hybrid quail and Japanese quail broodstock did not have a significant effect on fertility, embryo death, hatchability, hatch weight, female DOQ mortality and ratio. Although not significantly different, fertility and highest hatchability were the result of hybrid crosses of male quail and Japanese female quail (Coturnix coturnix japonica), namely in P4 with a 4: 4 sires and male ratio.
\end{abstract}

Keywords: Inbreeding, cross-breeding, Japanese quail, Hybrid quail 


\section{PENDAHULUAN}

Puyuh Jepang (Coturnix coturnix japonica) merupakan jenis unggas yang sangat disukai oleh peternak unggas selain ayam dan itik di berbagai daerah di Indonesia. Usaha peternakan puyuh bisa dilakukan mulai dari usaha kecil skala rumah tangga sampai skala besar untuk bisnis. Pemeliharaan puyuh di Indonesia sebagian besar ditujukan untuk menghasilkan telur, usaha breeding dan ada juga yang memanfaatkan sebagai penghasil daging. Hal ini terbukti dengan semakin banyaknya peternak yang memelihara puyuh dan juga meningkatnya konsumsi masyarakat terhadap telur, daging dan juga bermacam makanan hasil olahan puyuh.

Menurut Kaharuddin dan Kususiayah (2017), permasalahan yang terjadi saat ini di berbagai peternakan puyuh ialah penyediaan bibit sendiri sebagai indukan dengan cara perkawinan yang ada hubungan kekerabatan dekat (sedarah) tanpa persilangan dengan bibit baru dari luar. Akibatnya bibit-bibit yang dihasilkan dari hasil perkawinan tersebut mengalami kecacatan karena pengaruh inbreeding yang telah melampaui batas. Selain itu perkawinan secara inbreeding juga akan menutup kemungkinan untuk memperoleh bibit-bibit puyuh baru yang lebih unggul (Hybrid).

Salah satu upaya untuk meningkatkan kualitas puyuh yaitu dengan dilakukannya perkawinan silang (Cross Breeding) pada indukan puyuh. Perkawinan silang ini sangat baik jika dilakukan antara dua jenis puyuh yang memiliki kelebihan yang berbeda seperti puyuh Jepang (Coturnix coturnix japonica) dan puyuh Hybrid. Puyuh hybrid merupakan hasil perkawinan puyuh lokal dengan puyuh Jepang (Coturnix coturnix japonica). Beberapa kelebihan puyuh hybrid yaitu konsumsi pakan yang rendah dan memiliki daya tahan tubuh yang lebih baik.

\section{MATERI DAN METODE}

\section{Tempat dan Waktu Penelitian}

Penelitian ini dilaksanakan di Laboratorium Lapangan Peternakan (LLP) Program Studi Peternakan, Fakultas Pertanian, Universitas Syiah Kuala, Darussalam Banda Aceh. Penelitian berlangsung selama 38 hari mulai tanggal 2 Juli sampai 9 Agustus 2018.

\section{Materi Penelitian}

Materi yang digunakan dalam penelitian ini adalah 40 ekor puyuh jantan Hybrid dan 64 ekor puyuh betina Jepang (Coturnix coturnix japonica). Puyuh tersebut dibeli dari salah satu pusat pembibitan puyuh yang ada di Ajun, Aceh Besar.

\section{Alat dan Bahan Penelitian}

Alat-alat yang digunakan dalam penelitian ini adalah kandang ukuran $180 \mathrm{~cm} \times 150 \mathrm{~cm} \times$ $70 \mathrm{~cm}$ yang disekat sebanyak 16 unit, triplek penampung feses, timbangan digital, tempat pakan, tempat minum, dan mesin tetas.

Bahan-bahan yang digunakan terdiri dari pakan 324-1, pakan 511, Rodalon, Vitastress, sabun dan kapur.

\section{Parameter Penelitian}


1. Fertilitas adalah persentase telur yang fertil dari seluruh telur yang digunakan saat penetasan.

$$
\text { Fertilitas }=\frac{\text { Jumlah telur yang fertil }}{\text { Jumlah total telur }} \times 100 \%
$$

2. Mortalitas diperoleh dengan menghitung jumlah kematian dari semua DOQ yang menetas.

$$
\text { Mortalitas }=\frac{\text { Jumlah anak yang mati }}{\text { Jumlah telur yang menetas }} \times 100 \%
$$

3. Daya tetas $(\%)$ merupakan persentase dari banyaknya jumlah telur yang menetas yang berasal dari telur fertil. Dihitung dengan cara membandingankan jumlah telur yang menetas dengan telur yang fertil setelah masa pengeraman kemudian dikalikan 100\%.

$$
\text { Daya tetas }=\frac{\text { Jumlah telur yang menetas }}{\text { Jumlah telur yang fertil }} \times 100 \%
$$

4. Berat tetas diperoleh dari penimbangan berat badan setelah menetas yang dinyatakan dengan gram.

5. Rasio anak jantan dan betina didapatkan dengan menghitung jumlah anak jantan dan betina dalam bentuk perbandingan.

\section{Rancangan Penelitian}

Penelitian dilakukan secara eksperimental. Rancangan yang digunakan yaitu Rancangan Acak Lengkap dengan 4 perlakuan dan 4 ulangan.

\section{HASIL DAN PEMBAHASAN}

Hasil penelitian tentang pengaruh perbedaan rasio indukan puyuh jantan Hybrid dan puyuh betina Jepang (Coturnix coturnix japonica) terhadap fertilitas, kematian embrio, daya tetas, berat tetas, mortalitas dan juga rasio DOQ jantan dan betina disajikan pada Tabel di bawah ini. 
Tabel 1. Rataan Parameter Penelitian

\begin{tabular}{lcccc}
\hline \multirow{2}{*}{ Ulangan } & \multicolumn{3}{l}{ Perlakuan } & \multicolumn{3}{c}{} \\
\cline { 2 - 5 } & $\mathrm{P}_{1}$ & $\mathrm{P}_{2}$ & $\mathrm{P}_{3}$ & $\mathrm{P}_{4}$ \\
\hline Fertilitas & $86.08 \pm 10.60$ & $91.15 \pm 6.18$ & $89.9 \pm 10.59$ & $96.15 \pm 4.45$ \\
Kematian embrio & $32.43 \pm 12.42$ & $21.75 \pm 3.56$ & $25.10 \pm 6.99$ & $20.43 \pm 3.42$ \\
Daya tetas & $67.58 \pm 12.42$ & $78.25 \pm 3.56$ & $74.90 \pm 6.99$ & $79.58 \pm 3.42$ \\
Berat tetas & $7.30 \pm 0.50$ & $7.68 \pm 0.22$ & $7.68 \pm 0.39$ & $7.55 \pm 0.33$ \\
Rasio jantan & $27.50 \pm 8.66$ & $17.50 \pm 13.70$ & $12.75 \pm 8.82$ & $22.63 \pm 9.80$ \\
Rasio betina & $72.50 \pm 8.66$ & $82.50 \pm 13.70$ & $87.25 \pm 8.82$ & $77.38 \pm 9.80$ \\
\hline
\end{tabular}

Keterangan:

$\mathrm{P}_{1}$ : Persilangan puyuh jantan Hybrid dan puyuh betina Jepang (Coturnix coturnix japonica) (1:4)

$\mathrm{P}_{2}$ : Persilangan puyuh jantan Hybrid dan puyuh betina Jepang (Coturnix coturnix japonica) (2:4)

$\mathrm{P}_{3}$ : Persilangan puyuh jantan Hybrid dan puyuh betina Jepang (Coturnix coturnix japonica) (3:4)

$\mathrm{P}_{4}$ : Persilangan puyuh jantan Hybrid dan puyuh betina Jepang (Coturnix coturnix japonica) (4:4)

\section{Fertilitas}

Fertilitas merupakan hasil perbandingan antara semua telur yang fertil dengan telur yang ditetaskan dikali 100\% (Kaharuddin, 2017). Hasil analisis ragam nilai fertilitas telur puyuh hasil persilangan puyuh jantan Hybrid dan puyuh betina Jepang (Coturnix coturnix japonica) dengan rasio jantan betina : $\mathrm{P}_{1}(1: 4), \mathrm{P}_{2}(2: 4), \mathrm{P}_{3}$ (3:4) dan $\mathrm{P}_{4}$ (4:4) tidak menunjukkan pengaruh yang nyata $(\mathrm{P}>0,05$. Berdasarkan hasil penelitian yang diperoleh menunjukkan bahwa rataan persentase telur yang fertil dari tiap perlakuan yaitu 86.08, 91.15, 89.9 dan 96.15. Rataan persentase ini dianggap sangat baik karena menurut Abror et al. (2018) nilai fertilitas yang baik pada telur puyuh yaitu sekitar $68-78 \%$. Nilai rata-rata fertilitas telur puyuh pada perlakuan tercantum pada Tabel 1.

Berdasarkan data pada Tabel 1 di atas maka dapat diketahui rataan persentase fertilitas telur puyuh hasil persilangan puyuh jantan Hybrid dan puyuh betina Jepang (Coturnix coturnix japonica) tertinggi didapatkan dari perlakuan $\mathrm{P}_{4}$ (perbandingan pejantan dan betina 4:4) sebesar 96.15\%. Faktor yang disebutkan dalam Agromedia (2002) bahwa fertilitas telur puyuh juga dipengaruhi oleh sperma, umur indukan, pakan, musim dan suhu, sifat pejantan, waktu perkawinan serta tingkat produksi telur.

\section{Kematian Embrio}

Kematian embrio merupakan hasil perbandingan jumlah telur yang fertil namun tidak menetas dengan seluruh telur yang fertil (Shabirah, 2016). Berdasarkan hasil data statistik dapat dilihat bahwa persentase kematian embrio telur puyuh hasil persilangan puyuh jantan Hybrid dan puyuh betina Jepang (Coturnix coturnix japonica) dengan rasio 1:4, 2:4, 3:4 dan 4:4 tidak menunjukkan pengaruh yang nyata $(\mathrm{P}>0,05)$.

Persentase kematian embrio pada $\mathrm{P}_{2}-\mathrm{P}_{4}$ yaitu 21.75, 25.10 dan 20.43, angka ini termasuk rendah atau normal karena nilai daya tetasnya masih di atas $70 \%$. Sedangkan pada $\mathrm{P}_{1}$ persentase kematian embrio yaitu 32.43 dengan daya tetas $65.6 \%$, angka ini dianggap tinggi karena melebihi standar persentase daya tetas yang ditetapkan yaitu 70\% (Direktorat Pembibitan Ternak, 2011). Diduga penyebab kematian embrio yang cukup tinggi pada $\mathrm{P}_{1}$ dikarenakan pada $\mathrm{P}_{1}$ perbandingan 
pejantan dan indukan yang digunakan 1:4, sehingga daya hidup embrio lebih rendah saat penetasan.

\section{Daya Tetas}

Salah satu indikator dalam menentukan keberhasilan suatu penetasan adalah daya tetas. Daya tetas merupakan perbandingan antara jumlah telur yang menetas dengan telur yang fertil dan biasanya dalam bentuk persentase (Hamzah, 2017). Berdasarkan hasil analisis sidik ragam dapat diketahui bahwasanya nilai daya tetas telur puyuh hasil persilangan puyuh jantan Hybrid dan puyuh betina Jepang (Coturnix coturnix japonica) dengan rasio 1:4, 2:4, 3:4 dan 4:4 tidak menunjukkan pengaruh yang nyata $(\mathrm{P}>0,05)$. Hasil data penelitian dapat diketahui bahwa perlakuan P4 dengan perbandingan pejantan dan indukan 4:4 menghasilkan daya tetas paling tinggi mencapai 79.58\%, sedangkan pada $\mathrm{P}_{2^{-}} \mathrm{P}_{3}$ hanya 78.25 dan 74.90. Persentase $\mathrm{P}_{1}$ sedikit lebih rendah yaitu 67.58, hal ini dikarenakan pada $\mathrm{P}_{1}$ adanya anak puyuh yang mati dalam kerabang karena lengket dengan kulit dan bulu.

\section{Berat Tetas}

Berat tetas adalah bobot dari DOQ yang baru menetas namun bulunya telah mengering dan belum diberikan pakan dan minum (Hamzah, 2017). Berdasarkan hasil analisis sidik ragam dapat diketahui bahwa hasil persilangan puyuh jantan Hybrid dan puyuh betina Jepang (Coturnix coturnix japonica) dengan rasio 1:4, 2:4, 3:4 dan 4:4 tidak menunjukkan pengaruh yang nyata (P $>0,05)$ terhadap berat DOQ. Rataan berat DOQ dari $\mathrm{P}_{1}, \mathrm{P}_{2}, \mathrm{P}_{3}$ dan $\mathrm{P}_{4}$ yaitu 7.30 gram, 7.68 gram, 7.68 gram dan 7.55 gram. Diduga rasio indukan tidak memberikan pengaruh yang nyata terhadap berat tetas karena berat tetas sangat erat kaitannya dengan berat telur. Hal ini sesuai dengan pendapat Nugraha et al. (2016) bahwa berat tetas sangat besar hubungannya dengan berat telur, semakin berat telur yang akan ditetaskan maka berat tetas yang dihasilkan semakin besar.

Hasil Tabel 1 menunjukkan bahwa berat telur puyuh tertinggi yaitu pada $\mathrm{P}_{2}$ dan $\mathrm{P}_{3}$ dengan berat 7.68 gram, angka ini masih di bawah standar mutu yang telah ditetapkan. Salah satu penyebabnya yaitu rataan berat telur yang digunakan masih di bawah 10 gram yang terjadi akibat usia indukan masih tergolong muda ( 2 bulan). Hampir serupa dengan puyuh, pada ayam bobot DOC juga dipengaruhi oleh umur indukan, pada umur muda telur lebih ringan dibandingkan pada saat puncak produksi (North dan Bell, 1990).

\section{Mortalitas}

Mortalitas merupakan hasil perbandingan DOQ yang mati dengan seluruh DOQ yang menetas dikali 100\% (Sipayung, 2012). Berdasarkan hasil analisis sidik ragam dapat diketahui bahwas mortalitas telur puyuh hasil persilangan puyuh jantan Hybrid dan puyuh betina Jepang (Coturnix coturnix japonica) dengan rasio 1:4, 2:4, 3:4 dan 4:4 tidak menunjukkan pengaruh yang nyata $(\mathrm{P}>0,05)$. Rataan nilai mortalitas dari perlakuan 1 sampai perlakuan 4 berurutan yaitu 14.18, 21.68, 18.95 dan 26.25. Hasil pengamatan persentase mortalitas telur puyuh disajikan dalam Tabel 1.

Menurut Cahyono (2001) daya hidup DOQ paling tinggi yaitu pada perbandingan 1:1. hal ini tidak sesuai dengan data penelitian bahwa mortalitas paling rendah yaitu pada perlakuan perbandingan jantan dan betina $1: 4$ sebesar $14.18 \%$. Persentase mortalitas standar pada periode 
starter yaitu lebih kecil dari 3\% (Wuryadi, 2011). Biasanya angka mortalitas akan lebih tinggi pada fase starter karena dipengaruhi oleh sanitasi peralatan dan kandang serta suhu lingkungan. Sedangkan pada fase layer angka kematian sangat sedikit kecuali terserang penyakit seperti penyakit pernafasan (Wahyuri, 2014).

\section{Persentase Jantan dan Betina}

Berdasarkan hasil analisis sidik ragam dapat diketahui bahwa hasil persilangan puyuh jantan Hybrid dan puyuh betina Jepang (Coturnix coturnix japonica) dengan rasio 1:4, 2:4, 3:4 dan 4:4 tidak menunjukkan pengaruh yang nyata terhadap jumlah anak jantan dan betina $(\mathrm{P}>0,05)$. Hasil pengamatan rasio puyuh jantan disajikan pada 1. Data pada menunjukkan bahwa $\mathrm{P}_{1}$ memiliki jumlah jantan paling banyak yaitu $27.50 \%$ dan jumlah betina paling sedikit hanya $72.50 \%$. Sedangkan $\mathrm{P}_{3}$ memiliki jumlah jantan paling sedikit hanya 12.75 dan jumlah betina paling banyak $87.25 \%$. Keempat perlakuan tersebut jumlah anak betina lebih banyak dibandingkan dengan jumlah anak jantan. Kondisi tersebut menunjukkan bahwa rasio indukan tidak mempengaruhi rasio jantan betina DOQ dikarenakan tidak adanya perbedaan yang nyata antar perlakuan. Berikut rataan persentase rasio puyuh betina dapat diamati pada Tabel 1 di bawah. Menurut Hamzah et al. (2009) jenis kelamin unggas dapat dimanipulasi jika kandungan hormon testosteron dan juga hormon estrogen dalam tubuh dan yolk bisa diubah jumlahnya.

\section{KESIMPULAN}

Berdasarkan data hasil penelitian dapat disimpulkan bahwa Perbedaan rasio indukan puyuh Hybrid jantan dan puyuh betina Jepang tidak memberikan pengaruh yang nyata terhadap fertilitas, kematian embrio, daya tetas, berat tetas, mortalitas dan rasio DOQ jantan betina. Meskipun demikian fertilitas dan daya tetas tertinggi hasil persilangan puyuh jantan Hybrid dan puyuh betina Jepang (Coturnix coturnix japonica) yaitu pada $\mathrm{P}_{4}$ dengan perbandingan indukan dan pejantan 4:4.

\section{DAFTAR PUSTAKA}

Abror, F.N.A., L. Silitonga dan S. Wibowo. 2018. Pengaruh perbandingan jantan-betina dan lama penyimpanan telur terhadap daya tetas telur burung puyuh (Coturnix coturnix japonica). Jurnal Ilmu Hewani Tropika. 7 (1): 2.

Agromedia. 2002. Puyuh si Mungil yang Penuh Potensi. Agromedia Pustaka, Jakarta.

Cahyono, I.R. 2001. Pengaruh rasio pejantan dan betina burung puyuh terhadap fertilitas, daya tetas telur dan daya hidup DOQ. Skripsi. Jurusan Produksi Ternak Fakultas Peternakan Perikanan Universitas Muhammadiyah, Malang. 
Direktorat pembibitan Ternak. 2011. Pedoman Pembibitan Burung Puyuh yang Baik (Good Breeding Practice). Direktorat Jenderal Peternakan dan Kesehatan Hewan Departemen Pertanian, Jakarta.

Hamzah, S. 2017. Pengaruh umur induk terhadap fertilitas, daya tetas dan berat tetas telur burung puyuh. Skripsi. Program Studi Produksi Ternak Jurusan Produksi Ternak Universitas Hasanuddin, Makassar.

Hamzah, M., M. Sobri dan D.E. Prasetro. 2009. Evaluasi perbedaan level Zn pada kadar Zn, Estrogen, Progesteron, Aromatase darah, hati, telur dan ovarium ayam petelur. Laporan Akhir Hasil Penelitian Hibah Pascasarjana. Universitas Gadjah Mada, Yogyakarta.

Kaharuddin, D dan Kususiayah. 2017. Performan puyuh lokal asal Payakumbuh, Bengkulu dan hasil persilangannya. Jurnal Sains Peternakan Indonesia. 12 : 317-318.

North, M.O dan D.D Bell. 1990. Commercial Chicken Production Manual. $4^{\text {th }}$ Ed. Avi Book Nostrand Reinhold, New York.

Nugraha, M.F., R. Somanjaya dan D. Widianingrum. 2016. Performa telur tetas burung puyuh Jepang (Coturnix coturnix japonica) berdasarkan perbedaan bobot telur. Jurnal Ternak Tropika. 1: 79-80.

Sipayung, P.P. 2012. Performa produksi dan kualitas telur puyuh (Coturnix coturnix japonica) pada kepadatan kandang yang berbeda. Skripsi. Departemen Ilmu Produksi dan Teknologi Peternakan Institut Pertanian Bogor, Jawa Barat.

Shabirah, S., E. Sujana dan T. Widjastuti. 2016. Karakteristik hasil tetas puyuh petelur (Coturnix coturnix japonica) silangan warna bulu coklat dan hitam di pusat pembibitan puyuh Universitas Padjajaran. Student e-Journal. 3 (5): 1-10.

Wahyuri, M., E. Rahmadani dan Elfawati. 2014. Manajemen teknis produksi peternakan puyuh (studi kasus di peternakan Masagena Kecamatan Tenayan Raya). Jurnal Peternakan. 1(11): 8-21).

Wuryadi, S. 2013. Beternak Puyuh. Agromedia Pustaka, Jakarta. 